\title{
Teaching A Hybrid MBA Course: A Case Study In Information Technology From The Student Perspective
}

Ellen D. Hoadley, Ph. D., Loyola College in Maryland, USA

\begin{abstract}
There is ongoing research into online, distributed, distance learning that has transitioned from mailed video tapes to fully-implemented web-based courses. Less research has been conducted on hybrid courses - those that combine face-to-face sessions with web-based sessions. This paper reports on a case study of a hybrid course that teaches Information Technology in an MBA program. Rationalization for the implementation of a hybrid course within a traditional MBA program is explained. Cautions and expectations from the literature are explored. Lessons learned from the student perspective are presented.
\end{abstract}

Keywords: online learning, distance education, MBA, hybrid course, blended course

\section{CONTEXT}

The Setting

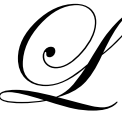

oyola College in Maryland is a comprehensive Jesuit university located in Baltimore with graduate program extension sites in Timonium to the north of the city and in Columbia to the south. Following in the 450-year tradition of St. Ignatius of Loyola, the university delivers liberal arts and professional education with particular emphasis on leadership, communication, reflection, and social justice development. Loyola first offered the Master of Business Administration (MBA) in 1967. The Executive MBA program was introduced in 1973, the first of its kind in the Baltimore-Washington area and the fifth executive MBA program in the country. All Loyola business programs are fully accredited by AACSB. There are currently about 1100 parttime evening MBA students and 150 executive students enrolled.

The competitive market for the MBA in the Baltimore/Washington corridor is experiencing an increase in providers and an increase in total market potential. Loyola's traditional MBA program has consisted of face-to-face sessions in two semesters with most courses comprised of 37.5 contact hours for 3 credits. There are also a number of alternative timing formats for the 3 credits such as 6-weeks, 3-weekend, 5-Saturdays, summer sessions, and international travel courses. Online courses have not been offered because our students report a high degree of satisfaction with the current formats, noting a reliance on in-class discussion to apply course material to different business environments. Since over $90 \%$ of our student population is working full-time, this application is an important part of the learning and networking experience. In addition, initial perception among the faculty has been that online courses can't have the rigor of in-class courses.

\section{What's a hybrid course?}

A hybrid course, sometimes called a blended course, is one that incorporates both face-to-face and online sessions. It generally follows a predescribed schedule. Sessions within the course may be synchronous or asynchronous depending on the technology available and the learning objectives of the course. The course described here consisted of five in-class sessions and ten online sessions that matched the 15 -week schedule of our spring semester in 2007. 


\section{Why a hybrid course?}

While some programs are facing financial pressures that make distance learning in all forms attractive (Fortino and Wolf, 2007), Loyola's interested in distance learning is more cautionary. Even so, several factors converged to provide the impetus for teaching a hybrid course in our evening MBA program.

1. More online programs competing for prospective students. Not only has the number of MBA programs in our region increased, but many of the additional programs offer online options. Our major competitor has announced a program focus in online learning. Loyola needs to balance its traditional face-to-face program with online offerings to attract students for whom this feature is important.

2. More requests for program flexibility from our existing students. Most of our current students do not want a fully-online program. However, flexibility is very important to overall MBA program satisfaction

3. More telecommuting and virtual team management in our business community. Our departmental advisory board reports an increasing number of dispersed project teams in their organizations. Since we're teaching management and leadership, we need to be able to teach the knowledge, skills, and applications of virtual teams. It makes sense to teach it by doing it.

4. More mature technology to support a hybrid course. Loyola has incorporated Blackboard as its course management system for over five years. The technology itself has matured in its advanced features and robustness. In addition, Loyola has increased the integration of our course management system in support of our MBA program as a whole. Faculty and student comfort with the tool makes migration to a hybrid course a smaller step than it might have been in the past.

5. Hybrid is a reasonable first step into online learning. There are many supporters of fully asynchronous online learning. However, the introduction of virtual community and online courses is easier to migrate and gain an audience for it if it fits snuggly within an existing program. A hybrid course fits this need.

6. A faculty member who wanted to try it. Faculty acceptance is the key to any program development. Having a spirit of adventure and an avid curiosity, I had been watching the online learning and virtual community research with great interest. More students were reporting challenges in their professional careers with dispersed teams and management. It was a good time to jump in.

7. An administration willing to support it. The dean's office provided support to attend a conference on online and hybrid courses as well as books and training materials. There was also intangible support to bridge campus politics plus personal encouragement.

\section{LITERATURE REVIEW}

The research on hybrid courses is limited and cautious. Riffell and Sibley (2005) reported that large undergraduate biology courses using a hybrid course format yielded equivalent or improved student performance on online assignments as compared to traditional courses, with upperclassmen performing better than freshmen. While a case-method MBA course doesn't readily simulate this environment, the improved performance at the upper levels may be extrapolated to more mature students like those in an MBA program who also are more likely to have a positive outcome than undergraduate freshmen. This article supports the expectation of positive learning outcomes using a hybrid format at the MBA level.

Chen et al. (2006) reported on a more representative class environment - case method asynchronous online sessions. Their results included increased participation and higher quality of participation in the online environment. However, this increase in case discussion did not yield as high learning gains as did the face-to-face environment. With this article came caution to expect a lower level of learning than in the traditional course setting. This expectation helped focus on clearly stating the expectations of each assignment, on providing students with specific grading rubrics for each assignment, and on remaining vigilant in guiding online case discussion for a maximum coverage of the learning objectives. The instructor was, perhaps, more intrusive than without this expectation, making sure that learning points were interjected if they were not raised by the students themselves in a timely manner.

In a context more specific to hybrid courses, DeNeui and Dodge (2006) examined the frequency with which students used online resources through Blackboard to expand the course content. In this study, the authors 
reported a positive correlation between usage of online materials and positive learning outcomes. This article indicated the importance of using multiple resources for student learning to keep the course engaging. This encouraged the provision of video, online learning objects, and additional written resources for student learning.

Macdonald and McNabb (2006) provided a course delivery model that was a continuum between a classroom-only model to a distance-learning-only model. Their model placed the hybrid course in the exact middle of the continuum and describes programs at Babson College, George Fox University, and Duke University as examples of this format. This provided face validity for such a program and placed it in the universe of teaching formats for the MBA program.

Koh et al. (2007) studied ways to motivate participation in and social identity with virtual communities. While not specifically focused on hybrid courses, the authors learned that engagement in an online course through asynchronous postings will be influenced by the IT infrastructure as well as the offline interactions of the members. The authors reported the most important factors in encouraging participation were the perceived usefulness of the postings and the social interactions that occurred outside the online sessions. In the case of the hybrid course reported here, the Koh study affected the choice of technology and the high attention paid to the face-to-face sessions. It was important to select the most neutral technology so as to have a minimal artifact effect. This led to the use of Blackboard, because this is the course management system Loyola students already use. Additionally, the face-to-face sessions were developed to maximize student interaction with each other. It was important to develop as much of a sense of community as possible given the limited duration of the course and the limited amount of interaction students had with each other prior to the onset of the course.

Fisher and Baird (2005) describe a proposed model for successful online learning design. They cite concerns about student drop-out rates in online courses (Carr, 2000) and state that "the issue of student retention will continue to grow as more institutions offer online learning opportunities (Fisher and Baird, 2005; p. 94). The authors prescribe relevance, accountability, motivation, and ownership as key elements of student retention in the online environment. Gaide (2004) also reports student expectations as a key element in the retention of students in online courses. The course examined in this study was a fully online course without options for a traditional course selection. However, these specific key elements also make the initial and ongoing face-to-face class sessions critical in sustaining student participation.

Finally, a pilot online session in an executive MBA section taught by the researcher indicated that those with learning preferences for oral communication would be less satisfied with a hybrid course. Those students who prefer visual communication of information may be more satisfied. Santo (2006) reviewed the learning style literature with a focus on online learning and reports that since the learning style assessments are self-reports, the results have been mixed. She concludes that computer skills and personal motivation have more of an effect than learning style on student satisfaction and success. Since enrollment in this section is voluntary and the technology is familiar, there was not any reason to believe that learning style would pose any problems for this hybrid course.

In conclusion, while the literature provides some insights into the potential success for a hybrid course in an MBA program, there are not enough specific guidelines. Most tips or pointers were provided by trade journals or popular press based on individual course experiences, rather than empirical studies. The research indicates that given the context for the hybrid course described here, in spite of the limitations noted, there is a reasonable probability for success.

\section{THE CASE STUDY}

\section{Preparation}

There were several preparatory steps taken before teaching in an online environment. Books and journals on both distance learning and virtual community provided baseline information on how to construct online learning modules. Sessions at the Information Systems academic conferences that presented research on distance learning and virtual community expanded the available information on course formation. A session of the Jesuit network dedicated to distance learning, especially in continuing education and graduate programs focused more specifically 
on learning for adults in virtual community and the particular needs of graduate students in distance learning. There were also some not-so-academic conferences that focused more on the nuts-and-bolts of how to implement distance learning. Finally, participation in an online course (Competence Assessment in Distributed Education) expanded the instructor's ability to assess learning in this different environment. All of these preparations provided valuable lessons into what makes distributed education work.

\section{The Course}

As an instructor preparing to provide this hybrid course for the first time, it was inevitable to compare the new format with traditional sections of the same class. The course is taught using the case method with extended class discussion to guide the students to the learning outcomes embedded in the case materials. Because this course is in the core of the MBA, students must achieve the learning objectives as well or better than in the traditional course to prepare for the rest of their program. As an experienced instructor of the course, the content was not in question, but many other issues needed to be deliberated and decided. How would students engage in a dialogue similar to and as effective as the traditional section? How would learning materials be presented beyond what the text offered? Could students work in groups or must all work be performed individually? How would student case analysis be facilitated through Blackboard (posting as opposed to discussion)?

\section{Course Content Presentation}

Since this course had been taught several times before, it was decided to re-use existing course material. Most of the material was in the form of PowerPoint slides with embedded hyperlinks. There were also some video materials and additional articles that are generally posted in the course management system for student reference. PowerPoint slides were used as is, using the Notes section at the bottom of each slide to present the material that would usually be delivered orally in class. Care was taken to include anecdotes and jokes carefully depending on what would be most appropriate in the online setting. Even though the slides are generally used to present the main points of the lesson, the additional notes were needed to be expansive, inclusive, and exhaustive. In addition, there were reference articles for student preparation. To make the class sessions more lively, links were provided to video on a streaming media server to show the principle players in the cases describing the situational outcomes.

\section{Course Discussion Facilitation}

The challenge in this course was to encourage participation and discussion because without it, there would be no learning outcomes. In traditional course sections, participation is not graded. Instead, students submit their notes following the class discussion to determine how many learning objectives they had met on their own before the discussion, and how many they had gleaned from the class discussion. With these notes, they are provided with feedback as to the quality and quantity of their demonstrated learning.

In the online setting, initial participation was fostered by grading both the quantity and quality of online postings. Students were provided with a heuristic, saying how many postings would give them the grade they expected. A particularly thoughtful posting would be worth double value, while a weak posting would be worth only half value. This was deliberately specific in quantity so they would post a sufficient number of responses to case questions to get the discussion going. It was deliberately vague as to quality to get them to provide thoughtful answers to the case questions, but also to provide encouragement to each other in the postings. This combination also provided sufficient leeway to adjust subjective grading should the postings be well outside the realm of expectations.

\section{Group Work}

In the traditional course section, the class is divided into groups of three to do an in-depth analysis of one of the cases for the semester. Because that would require students to meet together, this requirement was modified for the hybrid section. Instead, students were provided an online group chat room and discussion board for their group meetings. The requirement was still a more in-depth analysis and a posting during the first week that the assignment was due. The rest of the class, and the bulk of the discussion, would then take place in the next week following the 
initial analysis posting. This segregated the more in-depth analysis and set the stage for the online discussion the following week.

Grading

Once all the pedagogies were decided, the grading remained similar to the traditional setting. Each student was required to submit the same number and type of assignments as in the traditional setting. The only difference was that in the in-depth analysis, the students received individual grades instead of group grades for the assignment. Additionally, students received a participation grade for the case discussions. No such grade was given in the traditional section.

\section{Outcomes}

\section{Section Comparison}

At this writing, the hybrid course has been completed. Students were appropriately engaged throughout the semester. The outcome of the pilot study is biased because students volunteered for it. This section of students was compared to a comparable section of students taking the same course the semester previously. The instructor, text, assignments, and even instructional materials were the same for both sections. An analysis of the class characteristics using t-tests is provided in Table 1 below.

Table 1: Section Comparisons

\begin{tabular}{|l|c|c|c|c|c|}
\hline & $\begin{array}{c}\text { Traditional } \\
\text { Section }\end{array}$ & Hybrid Section & t-statistic & $\begin{array}{c}\text { p-value } \\
\text { (2-tailed) }\end{array}$ & df \\
\hline Number of Students (N) & 19 & 18 & & & \\
\hline Average Age & 33.79 & 30.44 & 1.6330 & 0.1112 & 36 \\
\hline Avg GMAT & 540.00 & 551.67 & 0.0651 & 0.9486 & 24 \\
\hline Avg Entering GPA & 3.38 & 3.21 & 1.392 & 0.1722 & 37 \\
\hline Avg. Current GPA & 3.72 & 3.72 & 0.1114 & 0.9119 & 37 \\
\hline Avg Yrs. Work Exp. & 13.2 & 8.9 & 2.1438 & $0.0393 *$ & 34 \\
\hline Avg Course Grade & 3.86 & 3.97 & 1.7328 & 0.0915 & 37 \\
\hline$* p<.05$ & \multicolumn{7}{l}{} \\
\hline
\end{tabular}

The findings of this analysis demonstrate no difference in the learning outcome as measured by course performance as indicated by the course grade. The only section factor that was different between the traditional and hybrid sections was years of work experience (significant at $p<.05$ level). There might be several explanations for this. Students with more work experience may not want to engage in the hybrid course for many reasons.

a) Lower comfort level with distance learning as a concept

b) Lower confidence in computer skills

c) Fewer family issues such as pregnancy or small infants

d) Less travel at work

For these reasons, there appears to be a selection bias that results in students with less work experience being more likely to register for the hybrid section. There's no way to know which of these issues could play a part in choosing a hybrid section without further study.

\section{Student Outcomes}

There were many positive and negative course outcomes from the instructor perspective reported in Hoadley (2007). Students were asked to write a reflection paper for the course that discussed what they had learned about the material, what they had learned about themselves, and what they had learned about their online learning experience. There were positive outcomes of the hybrid course from the student perspective that include: 
1) An overall positive response. Over half the class said that they were glad they had taken the hybrid course. Even more students reflected positively on the course, but didn't specifically say that they were glad they had taken it.

2) Some want more. Seven respondents indicated a desire to take more hybrid courses. The experience with this course was positive enough for them to seek other opportunities for online learning.

3) Some took more. Four respondents indicated that the hybrid course supported their ability to take an additional course this semester. Some students want to accelerate their programs. Hybrid courses allow them to do this by relieving some time management issues.

4) Flexibility was key. The feature that most students reported on favorably was the flexibility of the course. The asynchronous format provided the maximum flexibility of time and place for each student. This was the basic benefit of the format. There are many other distance learning platforms that enhance synchronous sessions with online classrooms, whiteboards, and discussion tools. However, this course was designed to maximize flexibility for the student. No synchronous sessions were provided except the face-to-face sessions. This accounts for positive reports of the hybrid course for students traveling and with specific family situations such as pregnancy and infants.

5) The expanded Power Point materials worked as an online lecture. There are many different tools that can be used to enhance online materials. Audio and video provide a more stand-up lecture look-and-feel to distance learning. However, these tools merely add a sound and a face to the learning materials. They don't change the content of the materials. Some students may have learned better with these tools if they were strong audio learners. However, most students adapted to the Power Point format, and visual learners may have even found it preferred over audio and video.

6) The Discussion Board worked. Even though the Discussion Board in Blackboard is not the most elegant discussion tool available, it worked for our class format. Two students reported learning more from the online discussions than they usually did from an in-class discussion. Students were able to engage in longer discussions and have a more iterative presentation of the case materials. More students, perhaps looking for that last comment to get their participation grade up, opted for relating the case materials to their own work experience. This enhanced the learning for all participants.

Table 2: Reported Student Features of the Hybrid Section

\begin{tabular}{|l|c|}
\hline Reflection Report Factors of the Hybrid Course & Number of Students Reporting \\
\hline I'm glad I took it. & 10 \\
\hline What I liked most was the flexibility of the course and the professor & 8 \\
\hline The posted PowerPoints worked well for me. & 7 \\
\hline I'd like to take more hybrid courses. & 5 \\
\hline I traveled a lot, so the hybrid format made it possible to keep up with the class. & 5 \\
\hline My family situation made this course appealing (new baby/pregnancy). & 4 \\
\hline I was able to take an additional course this semester. & 4 \\
\hline Once I posted my discussion points, I didn't return to the Discussion Board. & 4 \\
\hline Discussion board was challenging and didn't work well for my learning. & 4 \\
\hline I don't want to take any more hybrid courses. & 3 \\
\hline I missed face-to-face discussion and learning with my classmates. & 3 \\
\hline I needed more faculty face time & 3 \\
\hline Discussion board is good for structuring and encouraging class participation. & 2 \\
\hline I learned more from online discussions. & 2 \\
\hline It was more difficult to learn the lecture materials online. & 2 \\
\hline Course was challenging - more than a face-to-face section. & 1 \\
\hline I don't want the online course to reduce the value of my degree. & \\
\hline
\end{tabular}

However, as expected not all of the comments were positive. There were negative aspects of the hybrid section from the student perspective. These include: 
1) Some won't do it again. Even though some students readily reported the desire for more online learning, four students specifically stated that they didn't want to repeat the experience. For these students, the faceto-face environment was much preferred. Some even stated that they were surprised that the hybrid course took at least as much time to prepare for class and engage in the online discussion than would a face-to-face session. Some thought it took more time. The face-to-face section limits the discussion to the time constraints of the class session. The online discussion is not similarly limited. Students who confused flexibility with time savings were disappointed.

2) Lower satisfaction with discussion. Three students specifically mentioned missing the face-to-face discussion and in class learning from their classmates. Since the MBA program is part-time and $98 \%$ of the students are fully employed, each student brings a valuable learning context to the classroom. As they share this, the students recognize that they often learn as much from each other in applying concepts as they do learning from the instructor. This is an important feature of a part-time program.

Four students reported that the discussion board was challenging for them to navigate and work with. Additionally, four students reported that once they had posted the required submissions to the discussion board, they left and didn't return for that case. That means that they never saw the portion of the discussion that followed their posting. This is less than satisfactory for their learning.

3) Lower satisfaction with student/instructor interactions. In many ways, the instructor is the heart of the class, providing the pace and energy to the material and the learning. Students may not engage one-on-one with the instructor during class or after class; but they want the engagement of the faculty. Three students directly addressed this in their reflection papers saying they wanted more face-time with the instructor, not necessarily for anything specifically named. They just liked being engaged with the faculty member and thought that it enhanced their learning.

4) Lecture materials were challenging online. Even though seven students reported that the lecture materials were a good way to learn the materials in the hybrid format, two students reported it more challenging to learn from the Power Point slides online. Further investigation could reveal the underlying issue. It could be that students were viewing the slides through Blackboard which limits the functionality of PowerPoint. Saving the files to one's local computer, and launching the presentations through PowerPoint directly, makes navigating the presentations more intuitive to those accustomed to using PowerPoint.

5) Course was challenging overall online. Additionally, two students reported that the course itself was more challenging online. Again, further investigation could reveal the underlying issue. It's hard to know whether or not this is an instructor feature, an expectation mismatch, or a cognitive style issue.

6) Concern for the degree value. One student reported a concern that his degree might lose value by providing online learning within the MBA program. As mentioned earlier, this is one reason that Loyola has been cautious in introducing online sections. However, it's also interesting that this one student is a $5^{\text {th }}$ year student athlete who views his MBA as an extension of his undergraduate degree. The concern for degree value was not expressed by any of the part-time fully-employed MBA students.

\section{LESSONS LEARNED}

From the instructor perspective, the hybrid course has much to offer the MBA student and program. However, it's not an easy road. The preparation is challenging and the time commitment for the instructor can be daunting. There are no indicators that the hybrid section is any less rigorous than the traditional section of the same course. Instructors and students (and subsequently, university administrators) must understand that flexibility does not equate to time savings. The reward is in the flexibility of the course for the students and their enthusiasm in being part of a new venture for the university.

Students want more flexibility in a part-time program when home and work events make the traditional classroom setting difficult. They want to try new things and are motivated to learn the material even in a different setting. Students want to learn from each other. Even in the setting where there is less face-to-face interaction, they want to work with other students to perform high quality work and to support each other in case analysis. Students are motivated to do assignments thoroughly and to explore additional resources beyond what is required. However, when all is said and done, students want to know their classmates and their instructor. 
The students who have been attracted to a face-to-face learning environment are willing to suspend their normal learning environment for specific reasons. Two such reasons are high travel requirements for their jobs and family situations such as pregnancy and caring for infants. It is important for the instructor to set the expectations of the course carefully. Students must understand that greater flexibility does not mean less time spent on class preparation and online discussion. For many students, the limitless online discussion increases the time they will spend engaged with each other. They may be trading their work clothes for their bathrobes, but they'll still be working hard and spending long hours with the course.

\section{CONCLUSION}

This case study reported on the preparation and implementation of a hybrid course in Information Technology for an AACSB-accredited MBA program. The student motivations for such a course were presented, the student outcomes were listed, and lessons learned were discussed. Future research will include drilling down into the student evaluations and reflections on the hybrid course experience to determine the specific challenges that face students in the online learning environment.

\section{AUTHOR INFORMATION}

Ellen D. Hoadley, Ph. D., is Professor of Management Information Systems at Loyola College in Maryland where she has taught since 1988. Dr. Hoadley teaches Information Technology and Strategy in the MBA and Executive MBA programs, as well as Systems Analysis and Design at the undergraduate level. Her research areas include business process reengineering, requirements determination in systems analysis, and the use of color in the human/computer interface. Dr. Hoadley has published in journals such as Communications of the ACM, Journal of Business and Economic Perspectives, and Journal of Knowledge and Process Management.

\section{REFERENCES}

1. _Q "Quality Matters: Inter-Institutional Quality Assurance in Online Learning," www.qualitymatters.org, April 30, 2007.

2. $\quad$ Carr, S., "As distance Education Comes of Age, The Challenge is Keeping the Students," Chronicle of Higher Education, (46:23), p. A39.

3. Chen, Charlie C., Shang, Rong-An, and Harris, Albert, "The Efficacy of Case Method Teaching in an Online Asynchronous Learning Environment," Journal of Distance Education Technologies, (4:2), April/June 2006, pp. 72-86.

4. DeNeui, Daniel L. and Dodge, Tiffany L., "Asynchronous Learning Networks and Student Outcomes: The Utility of Online Learning Components in Hybrid Courses," Journal of Instructional Psychology, (33:4), December 2006, pp. 256-259.

5. $\quad$ Fischer, Mercedes and Baird, Derek E., "Online Learning Design that Fosters Student Support, SelfRegulation, and Retention,” Campus-Wide Information Systems (22:2), 2005, pp. 88-107.

6. Fortino, Andres and Wolf, Paige P., "Going the Distance," BizEd (6:1), January/February 2007, pp. 30-34.

7. Gaide, Susan, "Community College Identifies Student Expectations as Key Element in Online Retention," Distance Education Report, (8:15), August 1, 2004, pp. 4-6.

8. Hoadley, Ellen, "Teaching a Hybrid MBA Course: A Case Study in Information Technology," Proceedings of the Academic Business World International Conference, Nashville, TN, (2007).

9. Koh, By Joon, Kim, Young-Gul, Butler, Brian, and Bock, Gee-Woo, "Encouraging Participating in Virtual Communities," Communications of the ACM, (50:2), February 2007, pp. 69-73.

10. MacDonald, Diane B. and McNabb, David E., "Developing an MBA Alliance Model: Using Internet Capabilities to Enhance Graduate Education," Proceedings of the 2006, Proceedings of the Academic Business World International Conference, Nashville, TN, May 2006, pp. 460-491.

11. Riffell, Samuel and Sibley, Duncan, "Using Web-based Instruction to Improve Large Undergraduate Biology Courses: An Evaluation of a Hybrid Course Format," Computers \& Education, (44), 2005, pp. 217-235.

12. Santo, Susan A., "Relationship between Learning Styles and Online Learning: Myth or Reality?" Performance Improvement Quality, (19:3) 2006, pp. 73-88. 